\title{
Efémeros sinais
}

\author{
Rui Pina Coelho
}

Em grandes épocas históricas, altera-se, com a forma da existência colectiva da humanidade, o modo da sua percepção sensorial. 0 modo em que a percepção sensorial do homem se organiza - o medium em que ocorre - é condicionado não só naturalmente, mas também historicamente.

Walter Benjamin

> Descontextualizando, sem pudor, as palavras de Benjamin A tempestade, chegamos rapidamente onde esta epígrafe nos quer trazer de Shakespeare, - a percepção que temos do mundo é hoje, em grande enc. Giorgio Strehler, Piccolo Teatro de Milão no Teatro Lírico, 1978 (Giulia Lazzarini e Tino Carraro), fot. Ciminaghi. medida, condicionada pelas "novas" tecnologias. As nossas "circunstâncias históricas" são caracterizadas por inúmeras formas de mediação do visivel, dando uma nova leitura ao que de facto é perene e ao que é eterno.

Dentro deste quadro, a Internet, essa mutável rede de informação, veio alterar a relação do Teatro com os seus "sinais de cena" - veio ajudar a tornar menos dolorosa a relação que o teatro tem com o drama da sua efemeridade. Para além de registos vídeo e áudio, fotografias, revistas, programas, etc., a Internet possibilita hoje uma maneira de arquivar e ao mesmo tempo tornar disponivel a qualquer um os sinais efémeros do acontecimento teatral. Assim, trazemos aqui, a estas linhas, três exemplos de como através da "rede" a efemeridade do teatro é contornada. (A caracterização dos sítios aqui referidos foi realizada com base em visitas efectuadas entre Junho e Julho de 2004.)

0 primeiro exemplo é, sem surpresa, dado que vem do grupo que se queria "exemplar", o sítio do Piccolo Teatro di Milano (www.piccoloteatro.org). 0 primeiro aspecto a reter é o enquadramento que podemos dar à própria existência deste sítio. Sendo um ilustre representante de um projecto de "teatro de arte", faz da necessidade de publicação um dos factores basilares da sua actividade. Um projecto desta natureza pode deixar-se caracterizar por uma necessidade de fazer circular os conceitos e reflexões que o animam, de maneira a poder instruir crítica e público na sua gramática específica. É neste contexto que entendemos este sítio como mais um meio para explicitar uma ideia de teatro.

Mas apressemo-nos pois a entrar no sítio em questão. Apresentado exclusivamente em italiano, logo na página inicial, podemos aceder aos destaques da programação. Temos também várias "notícias" sobre a actividade do Piccolo, abarcando temas como lançamentos de livros, festivais, espectáculos, concertos musicais, etc. Todas estas entradas são apresentadas de maneira sucinta, com possibilidade de desenvolvimento caso o navegador esteja interessado. Ainda na página inicial, há uma entrada com o título "selecciona um espectáculo". (Optou-se por traduzir os "botões" apresentados na página.) Assim, podemos escolher qualquer um de entre os 51 (!) espectáculos previstos para as salas do Piccolo. Para qualquer um destes espectáculos são

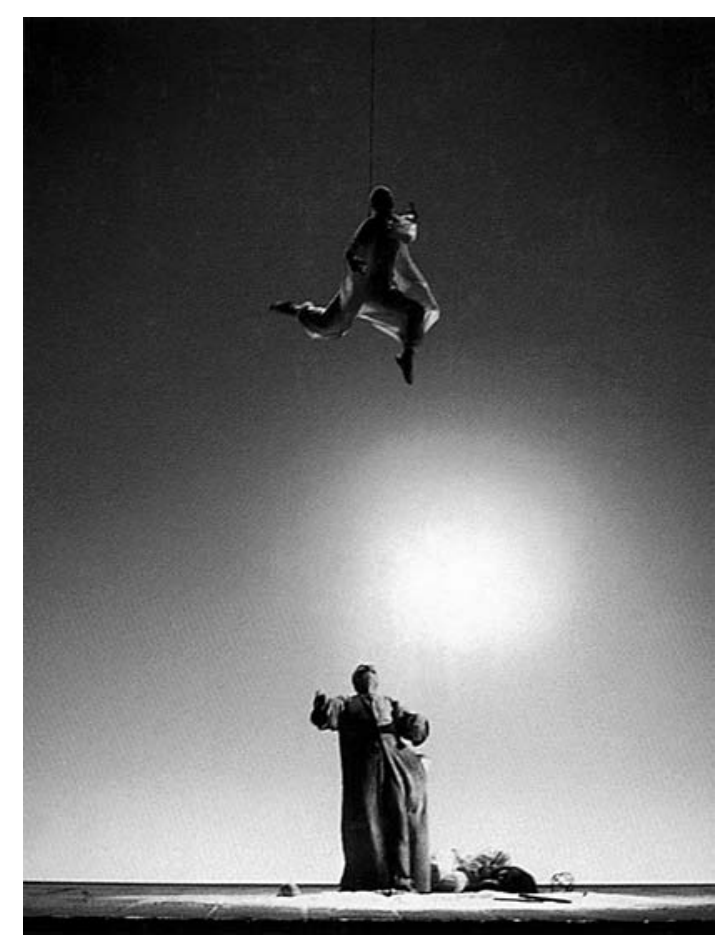

fornecidas fotografias, sinopses, datas e locais de apresentação, fichas artísticas e técnicas. Em alguns casos, há informação sobre o autor do texto, o director e/ou a companhia, citações da crítica e informações sobre o país de origem da companhia.

Para um utilizador que esteja em Itália ou que programe uma visita ao Piccolo Teatro, provavelmente o mais útil é o que ficou acima descrito e o que pode encontrar na "Agenda". Ai, estão todas as informações sobre a programação, bastante discriminadas, incluindo preços dos bilhetes e a possibilidade de os adquirir on-line.

Com tantas possibilidades de navegação, é fácil sentirmo-nos perdidos, sem sabermos como regressar à página de abertura. Então, terá chegado o momento de ir ao "mapa do sítio", que é bastante eficaz naquilo que pretende: situar o navegador de maneira a poder programar a sua navegação.

Dentro das componentes do sítio, e porque merece alguma explicação, destaquemos então a "Comunidade". Registando-se o navegador na Community del Piccolo - o 


Efémeros sinais $\mid$ Rui Pina Coelho $\mid$ Em rede $\mid$ Sinais de cena 1. 2004 $\mid$ cinquenta e nove

que pode fazer através do preenchimento de um pequeno questionário -, passa a receber notícias daquele Teatro via correio electrónico e a ter acesso a áreas reservadas do sítio.

E podemos entrar, pois, no que de mais rico este sítio tem. Na esquerda do ecrã, na página inicial, encontramos oito botões. Alguns deles, dão acesso a informação a que se pode ter acesso por outros caminhos, tais como o "Cartaz", a "Bilheteira", as "Informações" ou a "Comunidade". Nos restantes quatro - "Piccolo Teatro", "Arquivo", "Exposições Virtuais" e "Projectos especiais" -, encontramos informação que não é somente direccionada a um possivel espectador, mas também ao estudioso do fenómeno teatral. Assim, dentro dos "Projectos especiais" destacamos "Tempesta, musica da vedere": uma selecção de músicas para o espectáculo A tempestade (1978/79), de Shakespeare, com encenação de Giorgio Strehler. Integrado num esforço de catalogação e arquivo em formato digital de material histórico, este projecto vai muito para além disso disponibiliza a música de Fiorenzo Carpi e algumas interpretações em registo áudio, bem como partituras e excertos dos cadernos de encenação. Tudo isto permite ao navegador "ver", "ouvir" e "pensar" sobre a música que acompanhou este espectáculo, constituindo-se este material como uma fonte indispensável para a sua reconstituição.

Dentro das áreas reservadas podemos encontrar também algumas "Exposições Virtuais" que, através de diverso material iconográfico, convocam a história do Piccolo através dos espectáculos e das personalidades que mais o marcaram ao longo da sua existência, tais como Giorgio Strehler ou Luca Ronconi.

Acedendo a "Piccolo Teatro", encontramos textos sobre a história do grupo, bem como várias biografias. Encontramos também informações sobre a Escola de Teatro do Piccolo, incluindo condições de acesso, projecto didáctico e programas.

Mas o melhor está ainda por vir. Acedendo aos "Arquivos" (histórico e fotográfico), podemos fazer um percurso guiado através de cinco elementos: "Espectáculos", "Temporadas", "Autores", "Strehler" e "Artistas". Os materiais que podemos encontrar aqui vão desde registos vídeo e áudio, fotografias, apontamentos de encenação, esboços de cenários, sinopses, programas, registos de imprensa, cartazes, figurinos, etc. As possibilidades de cruzamento destes materiais são imensas. Cerca de 13.000 artigos digitalizados e 10.000 fotografias de cena permitem ao navegador acompanhar a história do

Piccolo, desde a sua fundação em 1947 até aos dias de hoje. A riqueza destes materiais é incomensurável e traz à luz do dia muitos dos "sinais de cena" que ficam geralmente na sombra.

0 segundo exemplo que aqui trazemos é bem diferente: o sitio Didaskalia - Ancient Theatre Today

(http://didaskalia.open.ac.uk), apresentado exclusivamente em língua inglesa. Trata-se de um jornal em edição electrónica dedicado ao estudo do Teatro Clássico, Grego e Romano, que comemora este ano o seu décimo aniversário. Mas para além do jornal - o coração deste sítio -, encontramos ainda outros itens que importa referir. Em "Listagens" acedemos a listas de espectáculos ou outros eventos relacionados com o Teatro Clássico, tais como publicações, conferências, festivais, oficinas, etc. Embora esta informação pretenda ser universal, a incidência recai claramente no mundo anglófono. Na denominada "Área de Estudo" podemos aceder a reconstruções virtuais em três dimensões de espaços teatrais, a um dicionário de Teatro Clássico, hiperligações para outros sítios relacionados e uma área de discussão interactiva intitulada "Ágord", onde estudantes, professores, investigadores e actores são convidados a, informalmente, trocarem algumas ideias e materiais. Mas tudo isto é um pouco periférico e trata-se visivelmente de um trabalho em curso, sendo manifestamente parca a informação que aqui é reunida.

Como já referimos, a alma deste sítio é o jornal - uma publicação académica inteiramente dedicada ao teatro,

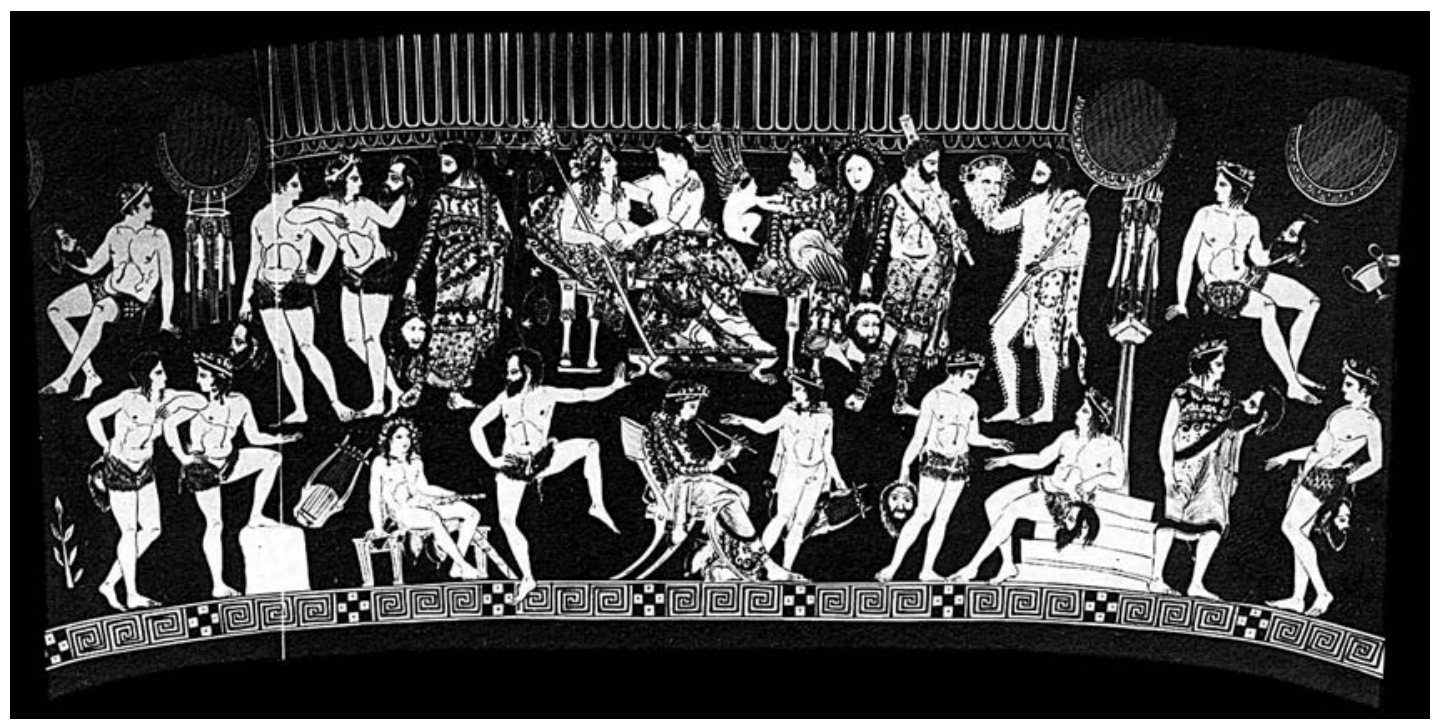


dança e música da Grécia e Roma Antigas. Os temas abordados são bastante variados: "A Tradução para Teatro", "Fusões do Teatro Grego e Asiático", "Corporizando o Teatro Antigo" ou "Desenvolvimentos e Tendências na Investigação Contemporânea", são apenas alguns exemplos. A abordagem desta publicação não é propriamente classicista, mas sim a de uma exploração do legado do Teatro Clássico na cena moderna. Os artigos ai publicados destinam-se a públicos muito variados, o que confere um certo eclectismo e dá um interesse suplementar a este periódico electrónico: professores, jovens estudantes ou profissionais da área encontrarão aqui motivos para uma navegação proveitosa. Em relação à navegabilidade, é extremamente simples pesquisar em Didaskalia, dado que o menu está sempre visível e os conteúdos são bastante claros.

0 último sítio que trazemos a estas linhas surgiu também há dez anos, mas na clássica forma de folhas de papel. Contudo, e dado que só teve um único número, rapidamente se tornou um objecto de coleccionador. Assim, só em Julho de 1997, Footlight Notes (http://footlightnotes.tripod.com) assumiu a sua forma electrónica, publicado em língua inglesa. E o que é? Trata-se de um arquivo iconográfico que aborda um período temporal limitado, que vai de 1850 a 1920. Recolhe imagens sobre vidas e carreiras de intérpretes que estiveram ligados a espectáculos de teatro, variedades, music-hall, vaudeville, comédias musicais, revistas e outros entretenimentos populares, no Reino Unido, América do Norte e em algumas zonas do antigo Império Britânico.

Podemos assim aceder a galerias de fotografias onde desfilam actores e actrizes, bailarinas, cantoras e acrobatas. 0 contributo deste sítio para o estudo da iconografia teatral é óbvio. Assistimos aqui também a um trabalho em curso, dado que, apesar das suas 315 páginas, os seus responsáveis manifestam a vontade de continuar a crescer.

Mas não encontramos só fotografias. Podemos consultar programas de espectáculos, artigos, capas de revistas, fotografias de cena, cartazes, postais, etc., para além dos populares retratos e fotografias de promoção de espectáculos

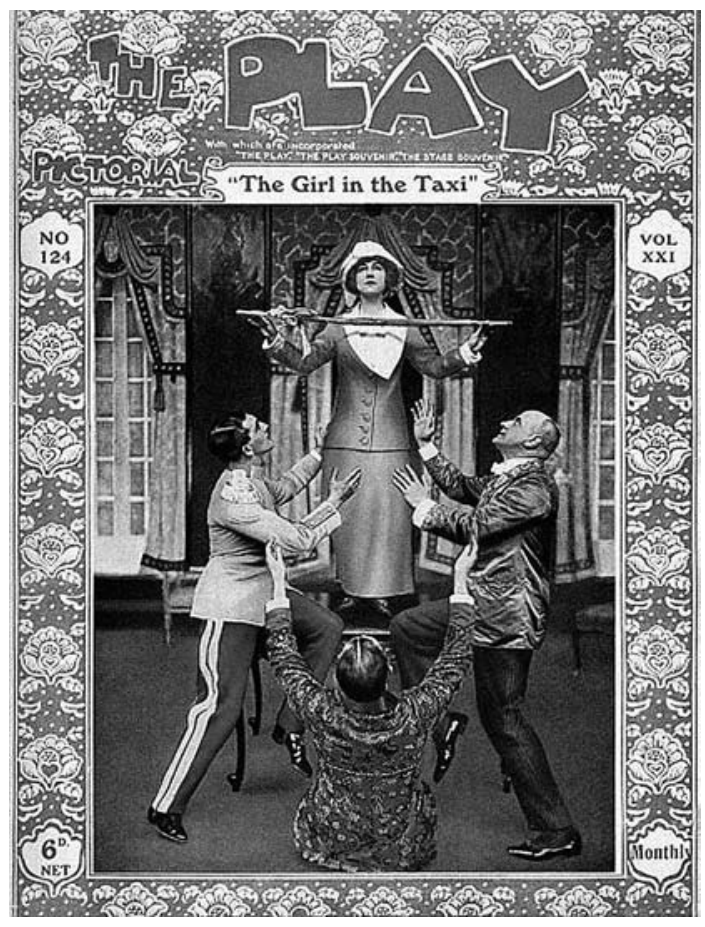

(ou de actores) em que os intérpretes posam envergando os figurinos dos papéis que interpretavam na altura (ou que os popularizaram). Mas a variedade dos materiais é muito maior e merece uma visita com tempo. Destaque-se o cuidado de apresentar ao navegador o material exposto. Quer através de uma biografia, de uma sinopse ou de uma qualquer outra explicação, todos os materiais vão sendo descritos, o que torna este sítio algo mais que um mero arquivo de imagens. Como um pequeno bónus, o navegador pode encontrar ainda alguns registos áudio de canções interpretadas em musicais do princípio do século.

Estes três sítios - e outros, claro! - vão captando o rasto que o teatro deixa atrás de si e vão recolhendo os sinais da sua efemeridade. A "rede" torna-se uma ferramenta contra o esquecimento $\mathrm{e}$, mais do que isso, uma forte aliada dos estudos de teatro na preservação da memória. E isso muda (tem que mudar) a nossa própria relação com a efemeridade teatral. 